\section{$\underset{\substack{\text { hommes } \\ \text { \& migrations }}}{ }$}

\section{Hommes \& migrations}

Revue française de référence sur les dynamiques

migratoires

$1278 \mid 2009$

Histoire des immigrations. Panorama régional

\title{
Rénia Aouadène, Nedjma et Guillaume
}

Éd. Marsa, 2009, 92 pages, 13 euros

\section{Mustapha Harzoune}

\section{OpenEdition}

12 Journals

\section{Édition électronique}

URL : http://journals.openedition.org/hommesmigrations/278

DOI : 10.4000/hommesmigrations.278

ISSN : 2262-3353

Éditeur

Musée national de l'histoire de l'immigration

Édition imprimée

Date de publication : 1 mars 2009

Pagination : 270

ISSN : 1142-852X

\section{Référence électronique}

Mustapha Harzoune, «Rénia Aouadène, Nedjma et Guillaume », Hommes \& migrations [En ligne], 1278 2009, mis en ligne le 29 mai 2013, consulté le 22 septembre 2020. URL : http://

journals.openedition.org/hommesmigrations/278 ; DOI : https://doi.org/10.4000/hommesmigrations. 278

Ce document a été généré automatiquement le 22 septembre 2020.

Tous droits réservés 


\title{
Rénia Aouadène, Nedjma et Guillaume
}

\author{
Éd. Marsa, 2009, 92 pages, 13 euros
}

Mustapha Harzoune

\section{RÉFÉRENCE}

Rénia Aouadène - Nedjma et Guillaume, Éd. Marsa, 2009, 92 pages, 13 euros

1 Marseillaise, enseignante en lycée professionnel dans les quartiers Nord de la cité phocéenne, Rénia Aouadène signe ici son premier roman après un recueil de nouvelles et une pièce de théâtre parus chez le même éditeur.L'écriture sent sa salle de classe et le texte n'est pas exempt de passages surprenants ou de maladresses comme ce tout premier dialogue entre Nedjma et Guillaume: "Je viens d'un pays où les mosquées se multiplient de jour en jour comme si elle pouvait [sic] se substituer au pain qui manque tant à mon peuple !" Bien, en guise d'entrée en matière, il faut désirer aller plus avant...

2 Pourtant, le personnage de Nedjma prend forme. Nedjma est une Algérienne en vacances à Marseille. Dans une église, elle rencontre Guillaume, le prêtre du lieu. Elle, la musulmane, y est entrée pour un moment de paix, lui, le prêtre, troublé, se surprend à quelques regards et élans nouveaux.

3 Une autre histoire se glisse au creux du récit: Djanina est d'une autre génération, celle de la guerre d'indépendance. La jeune Algérienne s'était engagée dans la lutte armée. Ces pages, souvent dithyrambiques et pompeuses, notamment en ce qui concerne la figure de Messali Hadj, sont sans originalité. Mais ici se niche, dans le secret d'une histoire familiale, le lien avec Nedjma et Guillaume : en prison, Djanina rencontra un médecin originaire des Cévennes avec qui elle eut un enfant. Ce fils d'un Roumi et d'une Algérienne vivra, élevé par la famille de Djanina. "Cet enfant [...] sera la preuve, la trace que notre amour fut un temps possible", dit Djanina. Comme un lointain écho, Nedjma lui répond: "Si les Algériens pouvaient! Il n'y a pas de peuple en ce monde qui soit issu d'un mélange aussi multiple. De nombreux conquérants ont traversé cette terre, certains sont restés, d'autres sont repartis mais nous avons intégré au fil des siècles toutes ces cultures. Nous sommes un et multiple." 
4 L'histoire entremêlée de la France et de l'Algérie continue de s'écrire, incarnée par les liens que tissent, petit à petit, Nedjma et Guillaume. Entre eux, il est d'abord question de discussions théologiques, du sort des femmes en terre d'islam - "parler avec les hommes, tel est le problème dans les pays musulmans"-, du retour obligé sur le mythe andalou et de l'Algérie de Bouteflika qui a "permis aux chiens de retourner dans leur niche pour y couler des jours heureux, avec la bénédiction des maîtres... telle est ma terre, nous n'en sortirons jamais!" dit Nedjma.

Bien trop démonstratif par endroits, l'intérêt du livre tient dans ce lien qui s'esquisse, les doutes et cette force souterraine qui poussent Nedjma et Guillaume irrésistiblement l'un vers l'autre, bousculant les tabous et bravant les interdits des leurs.Marsa est une maison d'édition spécialisée dans la littérature algérienne. Depuis bientôt treize ans, elle a publié bien des auteurs, jeunes dans la carrière ou confirmés. Elle édite également la revue Algérie Littérature Action dont le dernier numéro ( $\left.n^{\circ} 125 / 126\right)$ consacre de nombreuses pages au peintre Affif Cherfaoui et à ses œuvres, lumineuses et colorées. Comme à son habitude, le lecteur pourra y découvrir des nouvelles et des poésies inédites. À noter un texte d'Anouar Benmalek sur "la malédiction d'être arabe, et de quelques moyens pour un écrivain d'y échapper". 